\begin{tabular}{cc} 
UNIVERSITA \\
DEGLISTDI \\
DI TORINO \\
$\begin{array}{c}\text { ALMA UNIVRSIIAS } \\
\text { TAURINENSIS }\end{array}$ \\
& ECONOMICS AND STATISTICS \\
& WORKING PAPER SERIES \\
Founded in 1404 & Quaderni del Dipartimento di Scienze \\
Economico-Sociali e Matematico-Statistiche & ISSN 2279-7114 \\
\hline
\end{tabular}

\title{
HOW ENTRY INTO PARENTHOOD SHAPES GENDER ROLE ATTITUDES: NEW EVIDENCE FROM LONGITUDINAL UK DATA
}

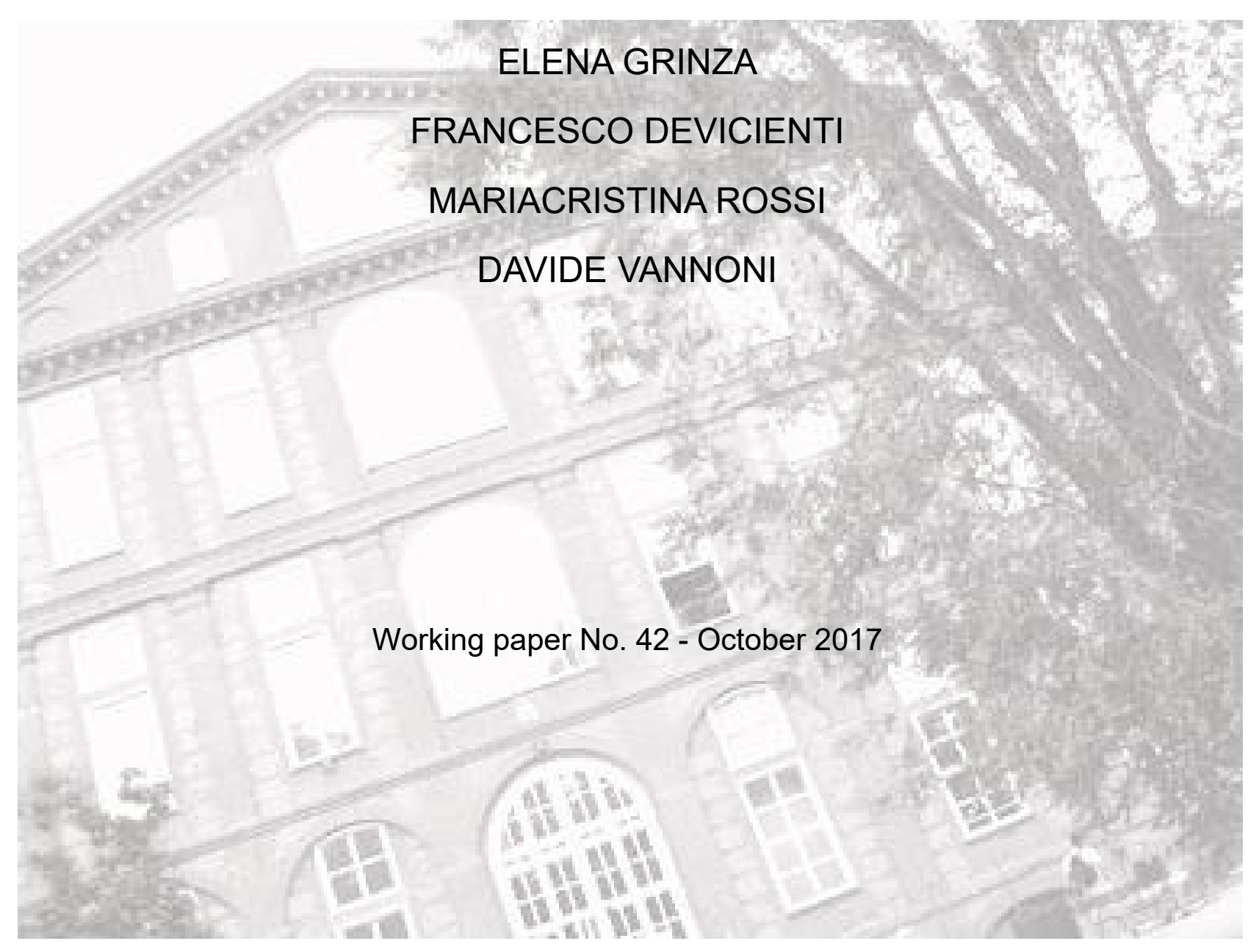




\title{
How Entry into Parenthood Shapes Gender Role Attitudes: New Evidence from Longitudinal UK Data
}

\author{
Elena Grinza ${ }^{\mathrm{a}, *}$, Francesco Devicienti ${ }^{\mathrm{a}, \mathrm{c}}$, Mariacristina Rossi ${ }^{\mathrm{b}, \mathrm{c}}$, Davide Vannoni ${ }^{\mathrm{a}, \mathrm{c}}$ \\ ${ }^{a}$ Department of Economics, University of Turin, Corso Unione Sovietica 218 Bis - 10134, Turin (Italy) \\ ${ }^{b}$ Department of Management, University of Turin, Corso Unione Sovietica 218 Bis - 10134, Turin (Italy) \\ ${ }^{c}$ Collegio Carlo Alberto, Via Real Collegio 30 - 10024, Moncalieri (Italy)
}

\begin{abstract}
Attitudes of women and men about how paid and unpaid work should be divided in the couple largely determine women's earnings and career prospects. Hence, it is important to understand how people's gender role attitudes are formed and evolve over the lifetime. In this paper, we concentrate on one of the most path-breaking events in life: becoming a parent. Using longitudinal panel data for the UK, we first show that, in general, entry into parenthood significantly shifts women's attitudes toward more conservative views, while leaving men unaffected. We also show that the impact on women emerges only after some time from the childbirth, suggesting that attitudes change relatively slowly over time and do not react immediately after becoming a parent. Finally, we show that the impact gets large and strongly significant for women and men whose prenatal attitudes were progressive. In particular, we find that the change in attitudes for such individuals increases as the postnatal arrangements are more likely to be traditional. Overall, these findings suggest that the change in attitudes is mainly driven by the emergence of a cognitive dissonance. Broad policy implications are drawn.
\end{abstract}

Keywords: Gender equality, gender role attitudes, entry into parenthood, cognitive dissonance, changes in the hormonal production, Understanding Society (US) data set. JEL: J16; J13.

${ }^{*}$ Corresponding author: elena.grinza@unito.it 


\section{Introduction}

Even though cultural norms are changing toward more egalitarian views, most of the Western societies are still characterized by a traditional division of paid and unpaid care work, where the man primarily undertakes breadwinning activities, while the woman's job is mainly to look after the home and family. In fact, activity rates are by far lower among women than men: according to the OECD, the activity rate for men stood at $75.6 \%$ in the OECD countries in 2015, as compared to only $62.9 \%$ for women. In addition, many employed women work on a part-time basis. The OECD reveals that as much as $25.9 \%$ of women who were employed in the OECD area in 2015 worked part-time, as compared to only $9.5 \%$ for men. A traditional gender division of labor also appears if we consider the amount of time that women and men devote to unpaid work. The OECD reports that women across the OECD countries in the period 1998-2009 spent on average 4.5 hours per day on unpaid work, as compared to only 2.2 hours for men.

This unequal division of paid and unpaid work makes women economically and socially weaker than men. Women's risk of poverty is higher, since they more often do not work, getting no wage, or work on a part-time basis, getting only a fraction of the full-time wage (Gornick, 2004). In addition, part-time work can be associated with pay penalties and can lead to skills and career stagnation (Hirsh, 2005; Manning and Petrongolo, 2009; Russo and Hassink, 2008). Also, since unpaid work is mostly on their shoulders, working women may experience difficulties in combining paid and unpaid work, thus limiting their involvement into the job and the possibility of career enhancements and wage increases (Evertsson, 2012). Moreover, the traditional view about the gender division of labor is likely to bring about discriminatory behaviors toward women (especially mothers) who choose to work, in relation to pay, career prospects, or inclusion in training activities (Budig and England, 2001; Correll et al., 2007; Gangl and Ziefle, 2009; Wozny and Schneider, 2014). It also creates stereotypes about what is suited for females and males, at work already during the childhood of an individual (Chalabaev et al., 2013; Cvencek et al., 2011; Pomerleau et al., 1990). In particular, gender stereotypes influence the educational choices of girls and boys. Girls tend to be underrepresented in many technical degrees, such as Engineering and Sciences, and overrepresented in degrees such as Humanities and Education (Turner and Bowen, 1999), a trend that decreases women's future earnings (Arcidiacono, 2004). What is more, traditional views of the gender division of labor shape institutions in a gendered way (Lewis, 1992), triggering a vicious circle that feeds economic inequality between women and men (Mandel and Semyonov, 2005; Pettit and Hook, 2005). In fact, in more traditional contexts, public childcare facilities lack, paternity leaves

are uncommon, and flexible working time arrangements such as part-time work are mainly addressed to women rather than men, thus heavily conditioning women's economic outcomes. 
In sum, a society's view about the role of women sets the limits of women's possibilities, in terms of employment, earnings, and career prospects. It is, therefore, of crucial importance to understand how women's and men's attitudes toward the gender division of labor are formed and evolve.

Building on a small but compelling literature suggesting that life course experiences can be an important driver of individuals' attitude formation and change (e.g., Bolzendahl and Myers, 2004; Cunningham et al., 2005), here we examine the impact of entry into parenthood, arguably one of the most path-breaking events in life, on women's and men's gender role attitudes. Understanding how people's attitudes change after becoming a parent is particularly relevant because that is the moment in which family modes of dividing paid and unpaid work usually undergo strong modifications. Often, traditional arrangements prevail and women find themselves taking care of their child almost exclusively. Understanding how this may modify their (and men's) views about gender roles is of great importance to draw proper policy implications that can guarantee more gender equality.

Our paper contributes to the existing literature in several ways. Firstly, it provides robust evidence that individuals' gender role attitudes are not stable over the lifetime, but rather change after important life course events, such as the entry into parenthood. In fact, differently from most of the previous studies, our results derive from fixed effects regressions that, exploiting only within-individual information, permit to obtain a neater estimate of the true impact. Secondly, our paper gives new evidence for a country (the UK) that has been explored only little, thus widening our knowledge on how the entry into parenthood impacts on gender role attitudes. Third, we dig into the mechanisms at stake, constructing a theoretical framework that results into four hypotheses that we do test empirically. This allows us to provide a novel set of results that have broad policy implications.

The paper is structured as follows. After a brief review of previous empirical studies in the field (Section 2), we examine the mechanisms that can drive the impact of interest and draw a set of four testable hypotheses (Section 3). We then move to the empirical test of these hypotheses on recent UK data. We first present the empirical model and discuss identification issues (Section 4). We then present the data and describe the UK context (Section 5). Finally, we show and discuss our results (Section 6) and conclude (Section 7).

\section{Previous empirical studies}

As a society's view about the gender division of labor shapes economic and social prospects of women and men and many institutional settings, ranging from regulations about parental leaves to provisions of public childcare facilities, scholars from a variety of disciplines, including sociology, economics, and psychology, have studied how women's and men's gender role attitudes form and evolve over time. 
A first group of studies on gender role attitudes focuses on aggregate-level analyses, either exploring aggregate long-term trends (Cotter et al., 2011), or differences across cohorts (Ciabattari, 2001), or the importance of cohort replacements versus intra-cohort changes in explaining the aggregate change in attitudes (Brewster and Padavic, 2000; Brooks and Bolzendahl, 2004; Danigelis et al., 2007).

A second, smaller group of studies, to which our paper belongs, concentrate on individuallevel analyses, investigating how individuals' gender role attitudes are linked to several social structural characteristics, such as the educational level (Bolzendahl and Myers, 2004; Cunningham, 2008; Cunningham et al., 2005; Kane, 1995), employment (Berrington et al., 2008; Bolzendahl and Myers, 2004; Cunningham, 2008; Cunningham et al., 2005) and marital (Bolzendahl and Myers, 2004; Cunningham et al., 2005; Moors, 2003) status, and, of course, parenthood (Baxter et al., 2015; Cunningham et al., 2005; Schober and Scott, 2012).

While results from these studies point to substantial impacts of social structural characteristics on individuals' gender role attitudes, many of them rely on cross-sectional methods, that typically suffer from spurious relationships. In fact, engaging in certain behaviors, such as enrolling into higher education programs, searching for and getting a paid job, getting married, or having children, can be determined by the person's mentality. For instance, more openminded individuals may be more likely to enroll into higher education programs or search for and get a paid job (this is especially relevant for women) and, at the same time, may hold more progressive views on gender roles. On the contrary, more close-minded individuals may be more likely to get married or have children and, at the same time, may hold more traditional positions about gender roles.

A way to remove such spurious relationships is to resort to longitudinal data and estimate how gender role attitudes change after the occurrence of a certain event (for instance, the attainment of an educational qualification, a change in the employment or marital status, or the entry into parenthood) for each single individual. Since the same individual is compared before and after the occurrence of the event of interest, any spurious relationship due to unobserved differences in mentality between individuals is removed. This estimation method is commonly referred to as 'fixed effects regression'.

Building on this preliminary evidence that social structural characteristics may influence gender role attitudes, we use fixed effects regressions to reliably estimate the impact of entry into parenthood, one of the most important events in life, on women's and men's gender role attitudes.

Despite its relevance, only Baxter et al. (2015) analyze the impact of entry into parenthood using fixed effects regressions. Resorting to the Household, Income, and Labour Dynamics in Australia survey, they find that both women and men become significantly more traditionalist after they become parents and that there are not significant gender differences in the impact. 
Several studies, instead, explore such impact using cross-sectional methods. Even when inserting dynamic components that should account for differences in prenatal gender role attitudes, they still compare different individuals, thus not fully accounting for confounding unobserved differences in mentality across them. In general, anyhow, their findings indicate that traditional gender role views are positively related to parenthood. Bolzendahl and Myers (2004) use ordinary least squares regressions and report that traditional gender role attitudes are positively related to the number of children in the US; Corrigall and Konrad (2007) resort to US data on high-school leavers followed over a 14-year period and ordinary least squares regressions, finding that children are negatively associated with later gender egalitarianism for both women and men; using ordinary least squares regressions, Cunningham et al. (2005) provide no evidence that childbearing influence gender role attitudes during young adulthood in the US; using cross-sectional log-linear path models and German data on young adult women, Moors (2003) finds that childbearing is related to subsequent traditional family values; finally, using cross-sectional structural equation models and the British Household Panel Survey, Schober and Scott (2012) find that more traditional attitudes among women and men are more likely in couples where women's postnatal labor market participation and the use of formal childcare contradict their progressive prenatal attitudes, finding a preliminary support for the cognitive dissonance hypothesis (discussed later).

\section{Mechanisms and hypotheses}

Theoretical grounds are provided by the medical and psychological literatures, indicating two mechanisms through which the entry into parenthood may modify gender role attitudes.

On the one hand, medical research has discovered that new mothers experience a dramatic modification in their hormonal production that is able to affect behavior, in particular, increasing the sense of nurturance and protection and the physical attachment to the child (Fleming et al., 1997). It is possible that this process entails a modification of women's views about which parent is most suited for caring activities and how paid and unpaid care work should be divided in the couple toward more traditional positions. Men are also found to undergo changes in their hormonal secretions after they become fathers, though much smaller compared to women, that howsoever affect behavior, for instance, increasing their disposition to care for the child and the paternal attachment (Storey et al., 2000). As for women, it is possible that these changes modify men's views, but, in this case, toward more progressive positions. Since women's and men's hormonal production restores to normal levels after some time from the childbirth, it is likely that the change in attitudes stemming from hormonal modifications, if any, is mostly temporary and tends to disappear when hormonal levels return to normality.

On the other hand, the cognitive dissonance hypothesis, originally developed by Festinger (1957), states that, when an individual's beliefs are in contradiction with behavior, it emerges 
a cognitive dissonance. This situation creates psychological discomfort in the individual, which manifests itself in the form of anxiety, anger, or frustration. The way in which the cognitive dissonance is generally solved is by changing beliefs to make them become more consonant with behavior, which, instead, is usually more difficult to change (e.g., because it is externally constrained). Applied to our context, if the established arrangements in the society are such that the woman primarily looks after the child while the man primarily takes on breadwinning activities, as it is often the case, in general, new parents are expected take on more traditional positions, to adapt their attitudes to constrained traditional behavior. Traditional modes in the division of paid work and caring activities can be imposed due to gender stereotypes or institutional designs that, being shaped by the prevailing culture, are often gendered (Boeckmann et al., 2015; Del Boca et al., 2009). For instance, many couples may be forced to organize paid and unpaid care work in a traditional fashion because public childcare facilities might not be sufficient and private nurseries might be too costly. If the woman is the second earner in the couple, it may be economically more convenient if she retires from the labor market or reduces her working time to look after the child (Baker et al., 2008; Brilli et al., 2016; Connelly, 1992; Del Boca, 2002; Del Boca and Vuri, 2007). At the same time, men generally find themselves unable (or unwilling) to help women in looking after the child, since switching from a fulltime to a part-time contract is often associated with a stigma, hindering career enhancements and/or earning increases, and paternal leaves are usually uncommon and looked with askance by the firms (Brandth and Kvande, 2001, 2002). Since traditional arrangements entail bigger changes in women's rather than men's lives after the childbirth (are the women that would take care of the child for the most part, probably at the expense of their working life), women are expected to experience a higher dissonance. Consequently, the effect on attitudes stemming from cognitive dissonance is likely to be bigger for women compared to men. An important implication of the cognitive dissonance hypothesis is that the change in attitudes gets bigger as the dissonance between beliefs and behavior increases. Applied to our context, this means that the attitude change due to the entry into parenthood gets bigger (i) when prenatal gender role attitudes of the individual are more progressive and (ii) arrangements on how paid work and caring activities are split between the woman and the man in the couple after the childbirth are more traditional.

Summing up, the following four testable hypotheses emerge from our discussion.

H1: Women are expected to take on more traditional positions after the entry into parenthood (due to hormonal modifications and/or cognitive dissonance). On the contrary, the impact on men is more uncertain and can even be positive if hormonal changes are strong enough to compensate for cognitive dissonance.

H2: Women are expected to experience a stronger (negative) impact compared to men, since 
they both undergo a stronger modification in their hormonal production and a stronger cognitive dissonance.

H3: If hormonal modifications drive the impact, the attitude change following the childbirth is expected to be mostly temporary. On the contrary, if cognitive dissonance drives the impact, the attitude change is expected to be more lasting (at least for the period in which the child needs more care).

H4: If hormonal modifications drive the impact, the attitude change following the childbirth is expected to be independent of external factors (that is, it should be observed for all the individuals). On the contrary, if cognitive dissonance drives the impact, the attitude change is expected to get more pronounced as prenatal attitudes are more progressive and postnatal arrangements are more traditional.

\section{Empirical model and identification}

To estimate the impact of entering into parenthood on gender role attitudes, we start from the following model:

$$
G R A_{i t}=a+\beta * F I R S T C H I L D_{i t}+\eta_{i}+\epsilon_{i t}
$$

where $G R A_{i t}$ denotes the gender role attitudes of individual $i$ at time $t$; FIRSTCHILD $D_{i t}$ is a dummy variable taking the value of 1 if the individual $i$ enters into parenthood (that is, has the first child) by time $t$ and 0 otherwise; $\eta_{i}$ collects all the time-invariant (observed and unobserved) factors influencing gender role attitudes and maybe also the probability of becoming a parent, such as gender, birth year, birth place, cultural background, personal experiences and inclinations (that is, mentality); and $\epsilon_{i t}$ collects all the time-varying (observed and unobserved) factors influencing gender role attitudes and maybe also the probability of becoming a parent, such as education, marital status, area of residence, religious devotion, and unpredictable shocks.

Given that we could only control for some observable time-invariant variables such as gender and year and place of birth, we exploit the panel dimension of our data (that is, two waves) and consider Equation (1) in differences, so as to eliminate any element, both observed and unobserved, in $\eta_{i}$. As discussed before, this strategy allows us to obtain a neater estimate of the true effect. In fact, unobserved factors such as cultural, family, and individual backgrounds and experiences are likely to play a central role in determining both gender role attitudes and the probability of entering into parenthood, thus mudding the estimation of the true impact if not taken into account. In practice, we compare gender role attitudes of the same individual before and after the entry into parenthood, according to the following fixed effects regression: 


$$
G R A_{i t}-G R A_{i t-1}=\beta\left(F I R S T C H I L D_{i t}-F I R S T C H I L D_{i t-1}\right)+\epsilon_{i t}-\epsilon_{i t-1}
$$

If Equation (2) solves the problem of unobserved time-invariant heterogeneity among individuals (that is, it eliminates $\eta_{i}$ ), it may suffer from another endogeneity issue. Changes in time-varying factors occurring between the two waves (that is, $\epsilon_{i t}-\epsilon_{i t-1}$ ) can lead to a revision of the gender role attitudes and, at the same time, to a change in the probability of having the first child. To attenuate this possible source of bias, we control for several time-varying factors, which are known to affect gender role attitudes. They include education, marital status, area of residence, and religion. In fact, it may be that a change in the educational attainment (for instance, obtaining a degree) makes the individual more open to new ideas, also in relation to gender role attitudes, and increases the probability of having the first child shortly after, since the individual may have completed his studies. Also changes in the marital status (that is, being married versus living as a couple versus living as a single) may influence both gender role attitudes and the probability of entering into parenthood. For example, getting married is likely to increase the probability of having the first child (many people get married and then have their first child) and, at the same time, may result in more conservative attitudes, possibly because gender stereotypes become more pressing once married. It may also be that moving to countryside is associated with an increase in the probability of entry into parenthood (some people leave the city when starting a family) and, at the same time, to more conservative gender role attitudes, possibly because rural areas are characterized by stronger gender stereotypes. Similarly, changes in religious devotion may increase the probability of entering into parenthood and, at the same time, may lead to a reconsideration of gender role views toward more traditional positions. ${ }^{1}$ Therefore, the inclusion of these variables in our regressions limits the omitted variable bias, thus delivering a better estimate of the true impact.

\footnotetext{
${ }^{1}$ Also age is a critical variable that, in principle, should be included in the regressions. In fact, it may be that growing older modifies gender role attitudes in a more conservative way and also positively influences the decision of having the first child. However, since we restrict the sample to people having their first child between the first and the second wave (see Section 5), we do not include age in our regressions. This is due to the fact that the change in age is (almost) perfectly collinear with the entry into parenthood. Also changes in income may play a role in influencing gender role attitudes and the probability of having the first child. For instance, an increase in the household income may increase the probability of having the first child shortly after and, at the same time, it may change gender role attitudes of the woman and man in the couple. If the increase in income is attributable to the woman, views may become more progressive; on the contrary, if the man experiences such an increase, views may get more traditional. Though this argument would suggest that income may be an important variable to control for, we decide not to insert it in our regressions. In fact, it is by far more likely that changes in income happen as a result of the entry into parenthood (consider, for instance, the case in which the woman exits the labor market or reduces her working time due to the childbirth) and not the reverse.
} 


\section{The Understanding Society data and the UK context}

To perform our empirical analysis, we use Understanding Society (US), a uniquely rich individualand household-level panel data set for the UK. The US survey is conducted every year since 2009 on approximately 40,000 households (at wave 1), sampled on the basis of a complex representative probability design. Individuals aged 16 or more in the household are interviewed every year on a wide range of topics, including gender role attitudes, children, family arrangements, and employment.

As Australia, the nation considered by Baxter et al. (2015), the UK is a typical Western country, where traditional views of gender roles are still common. This is evident if we look at the employment patterns of UK women and at the UK institutional design concerning childcare facilities and parental leaves. As for the other Western countries, inactivity rates in the UK are by far higher among women than men. According to the OECD, $28.3 \%$ of women in the working age in 2015 in the UK were inactive, while the same figure for men was significantly lower (17.8\%). Part-time jobs are mainly occupied by women also in the UK. The OECD reports that as much as $37.7 \%$ of employed women were working on a part-time basis in 2015 in the UK, making up for $73.7 \%$ of the total part-time workforce, a slightly higher proportion compared to the OECD average (68.7\%). In the UK, unpaid work is also unbalanced to the disadvantage of women, even if to a lesser extent compared to the OECD average. The OECD reveals that, over the period 1998-2009, the UK women in the working age were spending on average about 2 hours per day more than men on unpaid work. The UK government spends only a tiny fraction (0.8\% in 2013) of its GDP on day-care facilities and early childhood education, anyhow slightly more than the OECD average (0.7\%). The greatest expense item (about $0.7 \%$ of the GDP) is early childhood education, provided to children between 3 and 5 years old. On the contrary, expenditure on day-care, aimed at children aged 0-2 years, is exiguous (less that $0.1 \%$ of the GDP), suggesting that public childcare facilities for very young children are often lacking. Finally, the UK government grants rather generous paid maternity leaves, amounting to 39 (partially) paid weeks available for mothers before and after the childbirth. On the contrary, paternity leaves are very modest: only 2 (partially) paid weeks are available for fathers during the first few months after the childbirth, a significantly lower amount compared to the other OECD countries which, on average, grant fathers slightly more than 8 (partially) paid weeks to dedicate to their newborn child.

In our empirical analysis, we restrict the attention to waves 2 and 4 of the US survey (referring to years 2010/2011 and 2012/2013, respectively), since information on gender role attitudes is only provided in these waves. Gender role attitudes are probed through four Likerttype statements, that respondents are asked to rate on a five-points scale ranging from 'strongly agree' to 'strongly disagree' in a self-completion section of the questionnaire. The statements 
are the following:

(i) A pre-school child is likely to suffer if his or her mother works;

(ii) All in all, family life suffers when the woman has a full-time job;

(iii) Both the husband and wife should contribute to the household income;

(iv) A husband's job is to earn money; a wife's job is to look after the home and family.

Where necessary, we recode responses so that a low value always means more traditional views, while a high value always represents more egalitarian views. To synthetically indicate the gender role attitudes of an individual, we construct a simple score variable by summing up the four items together. This score variable ranges from 4, that represents the most conservative view, to 20, indicating the most progressive view, with 12 meaning neutrality. We treat the score variable (and the single items) as ordinal variables, thus allowing us to apply simple linear estimation techniques, in our case, fixed effects regressions. Many researchers using Likert-type questions follow this approach (see, for instance, Baxter et al., 2015 and Frey and Stutzer, 2008). In fact, linear estimation is more practical, especially when it is fundamental to control for unobserved time-invariant heterogeneity, as in our case, and conclusions are mostly identical to those stemming from complex nonlinear models, such as binary or multinomial logit/probit models accounting for conditional individual fixed effects (Ferrer-i Carbonell and Frijters, 2004; Frey and Stutzer, 2000; Riedl and Geisheckerb, 2014).

Since we are specifically interested into the effect of entering into parenthood, rather than generically having a child, we restrict the attention to people having had their first child between waves 2 and 4 . This entails considering people in the fertility age ${ }^{2}$ who have never had children up to wave 2 and who have had their first child by the wave 4 . To identify whether the individual has had a child between waves 2 and 4, we resort to the information contained in the 'newmum' and 'newdad' variables, indicating whether the individual has had a child since the last interview. To assess whether the newborn child is the first, we use a series of variables present in the data to reconstruct the entire fertility history of the individual.

In sum, the final sample used in our analysis is composed of people in the fertility age (i) observed and having completed the self-completion questionnaire (the section of the questionnaire where gender role attitudes are probed) in wave 2 and not having had any children up to that wave and (ii) observed and having completed the self-completion questionnaire in wave 4 and having had their first child by that wave.

Hence, our sample is a perfectly balanced panel with two observations per individual. It collects 339 individuals, of which 191 are women and 148 are men. FIRSTCHILD $D_{i t}$ switches

\footnotetext{
${ }^{2}$ We select women having between 16 and 45 years and men having between 16 and 50 years by the wave 4 .
} 
from 0 to $1100 \%$ of the times and our estimate of the impact of interest is obtained from the comparison of attitudes before and after the entry into parenthood.

Table 1 shows summary statistics about gender role attitudes. The average value of the score variable (remember that it ranges between 4 and 20) stands at 14.39 for women and 13.90 for men, indicating a certain degree of progressivism in both sexes. Consistently with the fact that women are more exposed to gender role issues, they tend to exhibit more progressive attitudes compared to men. To better understand how gender role attitudes are structured, we also present average scores of each single statement, since each one measures a particular aspect of gender role attitudes. In fact, the first and second statements (that is, A pre-school child is likely to suffer if his or her mother works. and All in all, family life suffers when the woman has a full-time job.) are more related to parenting practices and, in particular, to whether the mother is more suited than the father to care for young children and the family in general. Differently, the third and fourth statements (that is, Both the husband and wife should contribute to the household income. and A husband's job is to earn money; a wife's job is to look after the home and family.) refer more to the gender division of paid and unpaid care work and, in particular, to whether the woman should mainly dedicate to caring activities and the man should primarily undertake breadwinning activities. Data show that attitudes are rather different when considering parenting practices versus gender division of labor, for both women and men. While women and men have, on average, more traditional views regarding which parent should take care of the children and family (that is, the mother), they seem more progressive concerning who should do paid work in the household (that is, both should contribute to the household income). This suggests that egalitarian views on the gender division of labor can coexist together with more traditional views about parenting practices (Sjöberg, 2010). This fact explains the relatively modest internal consistency (Cronbach's alpha equal to 0.63) of the four statements. While we believe that the score variable is howsoever a reliable overall indicator of the gender role attitudes of an individual, we also present estimation results for each single statement to examine whether the impact of entry into parenthood differs on the basis of the type of attitudes probed. The descriptive statistics also show that women hold, on average, more progressive (or, at least, equally progressive) positions compared to men in all the four statements of the questionnaire.

Table 2 presents summary statistics on the control variables. A great proportion of women and men in the sample are highly educated, holding a degree or a higher education qualification (71.5\% and $61.2 \%$, respectively). Most of the women and men in the sample live with their spouse $(62.1 \%$ and $68.6 \%$, respectively), some of them cohabit with their partner $(30.6 \%$ of women and $26.0 \%$ of men), and only $7.3 \%$ (5.4\%) of women (men) live as a single. ${ }^{3}$ The great

\footnotetext{
${ }^{3}$ Note that we remove individuals that were single in wave 4, when they have already had their first child.
} 
majority of individuals in the sample live in urban areas, while only slightly more than one fifth of them live in rural areas. More than a half of women and men in the sample declare themselves as not belonging to any religion. ${ }^{4}$

\section{Results and discussion}

Tables 3, 4, 5, 6, and 7 report our results. All these results come from fixed effects regressions, comparing gender role attitudes of each individual before and after he or she becomes a parent. They all control for changes in the educational attainments, marital status, area of residence, and religious devotion that may have occurred between waves 2 and 4 .

According to our first hypothesis, we expect that women become more traditionalist after they enter into parenthood, either because of hormonal changes or cognitive dissonance. This hypothesis is confirmed by our data: women are estimated to experience a significant change in attitudes toward more traditional positions after they become mothers by 0.494 points on the 16-point Likert scale (see the first column of Table 3).

We know that the impact on men, instead, is more uncertain. In fact, it is the result of two opposite forces: on the one hand, hormonal changes suggest a positive effect, while, on the other hand, cognitive dissonance points to a negative effect. Hence, the overall impact can either be positive, if hormonal changes prevail, negative, if cognitive dissonance prevails, or even null, if none prevails on the other. Results show that the impact on men is negative, though very small in magnitude (-0.016) and largely not significant, suggesting that, in fact, no effect prevails on the other (see the second column of Table 3).

Our second hypothesis suggests that the (negative) impact is stronger for women than men, because hormonal changes are dramatically higher for them and cognitive dissonance is arguably stronger for them (in the presence of traditional arrangements, women are those that see the most important changes in their lives, entailing dedicating much time and effort to raise the child and, eventually, the transition into inactivity or the reduction of working time). This hypothesis finds support in our data. If the impact on women is rather large in magnitude and significant, men, overall, experience no significant impact.

Table 4 shows whether the impact of entry into parenthood for women's and men's is different across the four statements. It allows us to explore whether attitudes toward parenting practices, on the one hand, and gender division of paid and unpaid care work, on the other

\footnotetext{
${ }^{4}$ We provide aside information on age and income, the two controls that we do not insert in our regressions for the reasons discussed above. Women in the sample are, on average, about 30 years old, while men are about 32 years old. Net personal income in the sample is, on average, 1,514.68 Pounds per month. Consistently with the fact that inactivity and part-time work rates are by far higher among women (especially, mothers) than men, women's net personal income is $31.6 \%$ lower compared to men $(1,269.74$ Pounds per month for women versus $1,856.05$ for men). In the average household of our sample, each adult member (having more than 16 years of age) can count on 1,559.02 Pounds per month.
} 
hand, respond differently to having the first child. First, we report that new mothers display a significant revision of their views for two out of the four statements probed, always toward more traditional positions. New mothers are estimated to become significantly more likely to think that the family life suffers if the mother works on a full-time basis (Column 2). Differently, they do not significantly modify their opinions about the idea that young children suffer if their mother works (Column 1). This suggests that new mothers become more supportive of the idea that what really damages children and family life is not generically their engagement into paid work, but rather into full-time work. New mothers become significantly and strongly less supportive of the idea that both the husband and the wife should contribute to the household income (Column 3). Instead, the coefficient associated with the idea that the husband's job is to earn money while the wife's job is to look after the home and family is negative but not statistically significant, even if only marginally (Column 4). Second, we report that new fathers display a significant revision of their views for only one out of the four statements probed, toward more progressive positions. In fact, there is evidence that new fathers become significantly less in agreement with the idea that the child is likely to suffer if his or her mother works. They display negative effects on all the other statements, which, however, are never statistically significant.

Up to this point, we have found that, in general, becoming a parent significantly shifts women's attitudes toward more traditional positions, while leaving men's attitudes essentially unchanged. As discussed before, two different mechanisms can explain the impact: it can either stem from changes in the hormonal levels or from the emergence of a cognitive dissonance due to imposed traditional arrangements. Exploiting hypothesis $\mathrm{H} 3$ and H4, now we try to assess which mechanisms operate behind the impact.

Hypothesis $\mathrm{H} 3$ predicts that, if hormonal changes drive the impact, the change in attitudes following the entry into parenthood is mostly temporary, while, if cognitive dissonance drives the impact, the change is expected to be more persistent over time. Table 5 shows patterns of the effect over time. We can distinguish individuals that had their first child between the waves 2 and 3 and those that entered into parenthood between the waves 3 and 4 . Hence, we can assess the impact on individuals who had their first child between 2 and 1 years before they are again observed in wave 4 and individuals who entered into parenthood between 1 and 0 years before. The impact on women is again negative in both cases, but it gains statistical significance only for women that had their first child between 2 and 1 years before, thus suggesting that the impact strengthens over time, rather than declining, consistently with the prediction of the cognitive dissonance hypothesis. For men, the impact remains largely not significant in both cases, thus not allowing to draw any conclusion on them.

Hypothesis $\mathrm{H} 4$ exploits an important implication of the cognitive dissonance hypothesis, that allows us to better capture the mechanisms at work. According to this implication, the attitude 
change is expected to be greater in individuals that experience a greater dissonance between prenatal beliefs and postnatal arrangements in the division of paid and unpaid care work that take place. In other words, we expect that, if cognitive dissonance drives the impact, the greatest attitude change is displayed by individuals that had prenatal progressive attitudes and, after the entry into parenthood, experience the external imposition of traditional arrangements. On the contrary, if hormonal changes drive the impact, the change in attitudes should show up similarly for each individual.

Table 6 presents a test of hypothesis H4. It first shows how attitudes of women and men that displayed prenatal progressive ideas change after the entry into parenthood. We define women and men as 'progressive' when their prenatal attitude score variable is greater or equal to 16. This amounts to require that the individual disagrees or strongly disagrees on all the (recoded) statements. Note that about $40 \%$ of the women in the sample enter this category, while the percentage for men is somewhat lower $(30.4 \%)$, consistently with the fact that men display a lower degree of progressivism compared to women. Results show that, consistently with the cognitive dissonance hypothesis, the women that were progressive before the entry into parenthood experience a strongly significant and large negative impact, revising their beliefs by as much as -1.782 points (Column 1, first part). Interestingly, a statistically significant and rather large negative impact emerges also for men (-1.196), suggesting that cognitive dissonance is also relevant to them (Column 1, second part). The effect, however, does not show up for the overall sample of men, possibly because progressive men are not as many as women and the impact on them is anyway smaller (-1.782 versus -1.196$)$. Subsequent columns test more directly hypothesis H4, investigating how attitudes of progressive people change when the likelihood of experiencing imposed traditional arrangements after the childbirth increases. We identify three situations consistent with this picture: (i) living in areas characterized by more conservative gender role views, where gender stereotypes get more tightening; (ii) living in areas characterized by low availability of external childcare, where institutional constraints pushing toward a traditional gender division of labor get stronger; (iii) living in areas characterized by low mothers' employment rates, where institutional factors and/or gender stereotypes get more pressing. Information on the gender role views, availability of external childcare ${ }^{5}$, and mothers' employment levels of a particular area is proxied using the complete US data set (waves 1 and 2). Local authority districts (i.e., municipalities) are the geographical unit of reference. Columns 2, 3, and 4 of Table 6 reports results for this exercise. Coherently with the cognitive dissonance hypothesis, we can see how the attitude change of progressive women and men become highest when they are more exposed to the imposition of traditional arrangements.

\footnotetext{
${ }^{5}$ External childcare includes any form of childcare carried out by someone different from the parents, including relatives, babysitters, and nursery services.
} 
Women living in conservative areas, where availability of external childcare services is scarce, and the employment of mothers is low, experience changes in attitudes between -2.179 and 2.544 points. Men also experience large changes, even if generally lower as compared to women.

Up to now, we have measured the likelihood of experiencing postnatal imposed traditional arrangements, using variables that are as exogenous as possible. This is done to preserve our results from potentially confounding relationships given by the fact that individuals experiencing bigger traditionalizations of attitudes (e.g., because of hormonal changes) are also more likely to voluntarily engage in traditional arrangements after the childbirth. Keeping this in mind, we can nevertheless investigate how attitudes of individuals that had prenatal progressive views react to the entry into parenthood when they experience traditional arrangements for real. If, on the one hand, we warn the reader of the spurious relationships that potentially can emerge, on the other hand, we think that, at least in the majority of cases, the attitude change would emerge as the result of imposed arrangements in this case, because we restrict the attention to individuals that before the childbirth had very progressive views.

We distinguish two situations that identify the emergence of traditional arrangements. Note that we restrict the following analysis to women, since to get the information on the emergence of traditional arrangements for men, we need to also observe their wife/partner, requirement that reduces the sample size too much to draw meaningful conclusions.

Firstly, we resort to the information on the use of external childcare. Women that do not receive any external help in caring their children, have to bear most of the burden of childcare, thus devoting much time and effort. Only in a few cases new mothers that do not resort to external childcare can count on the husband's or partner's help to care after the child. As much $77.4 \%$ of the new mothers in the sample that do not resort to external childcare declare themselves to be those mainly responsible for the childcare. Only $18.3 \%$ declare that they share childcare activities with their husband or partner, while a tiny fraction (3.2\%) report that their husband or partner is mainly responsible for the childcare. Since having no external help in the childcare is likely to arise from external constrains, rather than voluntary choices (especially for women that were progressive before the childbirth), we expect that women not using external childcare are more likely to experience a cognitive dissonance, and, consequently, a stronger impact compared to women resorting to external childcare. The first column of Table 7 provides a further indication that the cognitive dissonance might be the driving force. In fact, we estimate that women who held progressive views before the childbirth, experience a significantly higher change in attitudes when they do not resort to any form of external childcare (by -1.786 points). For them, the entry into parenthood is estimated to cause a strongly significant and large change (by $2.841=1.055+1.786$ points) toward more conservative attitudes.

Secondly, we use the information on the women's working status before and after the child- 
birth. Women that after the childbirth end into inactivity, sacrifice their working life for looking after the newborn child, thus experiencing traditional arrangements of paid and unpaid care work. Since entering into inactivity is often the result of economic considerations and constraints, rather than spontaneous decisions, we expect that these women experience a cognitive dissonance, leading them to revise attitudes in accordance with the traditional arrangements experienced. The second column of Table 7 suggests again that the impact stems from cognitive dissonance. In fact, we find that women having progressive views before the childbirth and experiencing a strong deterioration of their working conditions, passing from employment to inactivity, become significantly and largely more supportive of traditional views (by 1.704 points) compared to those not transiting into inactivity.

Taken together, these results provide evidence that cognitive dissonance is an important driver of attitude change. Traditional arrangements that are often imposed after the childbirth due to institutional settings and gender stereotypes, trigger women (and men, though by less) to become more supportive of such traditional arrangements. On the contrary, the hypothesis that the impact stems from changes in hormonal productions finds less support in our data.

\section{Conclusions}

Motivated by the great importance of the individuals' attitudes toward parenting practices and gender division of labor in determining women's economic and social outcomes, we explore how gender role attitudes of women and men change after a major life event: becoming a parent.

Differently from most of the previous studies, we fully exploit the longitudinal nature of our data and provide results that are robust to unobserved time-invariant heterogeneity (and several time-varying controls), that likely hinder the identification of the true impact.

We find that, in general, becoming a parent significantly shifts women's attitudes toward more traditional positions, while leaving men's attitudes essentially unchanged.

Exploiting two testable hypotheses that emerge from our theoretical discussion, we are able to investigate whether the impact stems from changes in the hormonal levels experienced by women and men after the childbirth or from the emergence of a cognitive dissonance due to imposed traditional arrangements taking place after the entry into parenthood. Our results point to a substantial role of cognitive dissonance in determining the attitude change. Externally imposed traditional arrangements emerging after the entry into parenthood trigger women to become more supportive of conservative positions.

Economic considerations and gender stereotypes emerging once entered into parenthood often result in a traditional division of paid and unpaid work in the couple, with women mainly looking after the newborn child and men primarily undertaking breadwinning activities. Institutions, that are still gendered in most of the Western countries (including the UK), contribute 
to the emergence of traditional arrangements once women become mothers. Paltry paternity leaves, lacking public childcare facilities and expensive private nurseries, and negligible male part-time work make most women's choice univocal: dedicating to childcare and sacrificing (part of the) working life. What is more, our findings give evidence that women do not react to imposed traditional (and harmful) arrangements, but rather contribute to propagate them.

Policy makers should devise policies aimed at interrupting such vicious circle, granting mothers the possibility to have a full working life, without being forced to choose between children and work. This task includes taking active steps to promote paternity leaves, male part-time work, and public childcare services, as well as measures to fight against deleterious gender stereotypes. 
Table 1: Descriptive statistics: gender role attitudes.

\begin{tabular}{|c|c|c|c|c|}
\hline & \multicolumn{2}{|c|}{ Women } & \multicolumn{2}{|c|}{ Men } \\
\hline & Mean & Std. dev. & Mean & Std. dev. \\
\hline Score variable (values between 4 and 20 ) & 14.39 & 2.76 & 13.90 & 2.90 \\
\hline Single items (values between 1 and 5 ) & & & & \\
\hline $\begin{array}{l}\text { (i) A pre-school child is likely to suffer if his or her } \\
\text { mother works. }\end{array}$ & 3.37 & 1.02 & 3.13 & 1.05 \\
\hline $\begin{array}{l}\text { (ii) All in all, family life suffers when the woman has } \\
\text { a full-time job. }\end{array}$ & 3.31 & 1.09 & 3.31 & 1.09 \\
\hline $\begin{array}{l}\text { (iii) A husband's job is to earn money; a wife's job } \\
\text { is to look after the home and family. }\end{array}$ & 3.72 & 0.98 & 3.67 & 0.97 \\
\hline $\begin{array}{l}\text { (iv) Both the husband and wife should contribute to } \\
\text { the household income. }\end{array}$ & 3.98 & 0.96 & 3.79 & 1.03 \\
\hline Number of observations & & 382 & & 296 \\
\hline Number of individuals & & 191 & & 148 \\
\hline
\end{tabular}

Source: US data set (waves 2 and 4 )

High values represent more progressive views, while low values indicate more traditional views.

Table 2: Descriptive statistics: control variables.

\begin{tabular}{l|c|c}
\hline \hline & Women & Men \\
\cline { 1 - 1 } Education & & \\
\cline { 1 - 1 } Highly educated & $71.5 \%$ & $61.2 \%$ \\
Low educated & $28.5 \%$ & $38.8 \%$ \\
\cline { 1 - 1 } Family status & $62.1 \%$ & $68.6 \%$ \\
\cline { 1 - 1 } Living with the spouse & $30.6 \%$ & $26.0 \%$ \\
Cohabiting with the partner & $7.3 \%$ & $5.4 \%$ \\
Living as a single & & \\
\cline { 1 - 1 } Area of residence & $76.2 \%$ & $78.7 \%$ \\
Urban area & $23.8 \%$ & $21.3 \%$ \\
\cline { 1 - 1 } Rural area & & \\
\cline { 1 - 1 } Religion & $45.8 \%$ & $41.5 \%$ \\
$\quad$ Not belonging to a religion & $54.2 \%$ & $58.5 \%$ \\
\cline { 1 - 1 } Number of observations & 382 & 296 \\
\hline \hline \multicolumn{2}{|l}{ Source: US data set (waves 2 and 4$)$} &
\end{tabular}


Table 3: The impact of entry into parenthood on women's and men's gender role attitudes; fixed effects regressions.

\begin{tabular}{|c|c|c|}
\hline \multicolumn{3}{|c|}{ Dependent variable: gender role attitudes (score variable; values between 4 and 20) } \\
\hline & Women & Men \\
\hline Entry into parenthood & $\begin{array}{c}-0.494^{* *} \\
(0.232)\end{array}$ & $\begin{array}{c}-0.016 \\
(0.250)\end{array}$ \\
\hline Control variables: & & \\
\hline Education: & & \\
\hline Highly educated & $\begin{array}{c}-4.607^{* * *} \\
(1.162)\end{array}$ & $\begin{array}{c}0.016 \\
(0.250)\end{array}$ \\
\hline Family status: & & \\
\hline Cohabiting with the partner & $\begin{array}{c}-0.042 \\
(0.620)\end{array}$ & $\begin{array}{l}-1.619 \\
(0.999)\end{array}$ \\
\hline Living with the spouse & $\begin{array}{l}-0.427 \\
(0.792)\end{array}$ & $\begin{array}{c}-2.093^{*} \\
(1.116)\end{array}$ \\
\hline Area of residence: & & \\
\hline Living in a rural area & $\begin{array}{c}0.300 \\
(0.969)\end{array}$ & $\begin{array}{c}-2.638^{* *} \\
(1.094)\end{array}$ \\
\hline Religion: & & \\
\hline Not belonging to a religion: & $\begin{array}{c}0.733 \\
(0.453)\end{array}$ & $\begin{array}{c}-0.161 \\
(0.652)\end{array}$ \\
\hline Number of observations & 382 & 296 \\
\hline Number of individuals & 191 & 148 \\
\hline Percentage of individuals becoming parents between the waves 2 and 4 & $100 \%$ & $100 \%$ \\
\hline
\end{tabular}

Source: US data set (waves 2 and 4)

Robust standard errors in parentheses; ${ }^{* * *},{ }^{* *}$, and ${ }^{*}$ denote, respectively, the $1 \%, 5 \%$, and $10 \%$ significance level. Highly educated people include individuals with a degree or more or with a higher education qualification below the degree level. The tiny fraction of people passing from the low to the high educational category $(1.2 \%)$ prevents from any interpretation of the coefficient associated with education, even if it is statistically significant. The reference group for the family status is living as a single.

Table 4: The impact of entry into parenthood on women's and men's gender role attitudes: separate analysis for each of the four statements; fixed effects regressions.

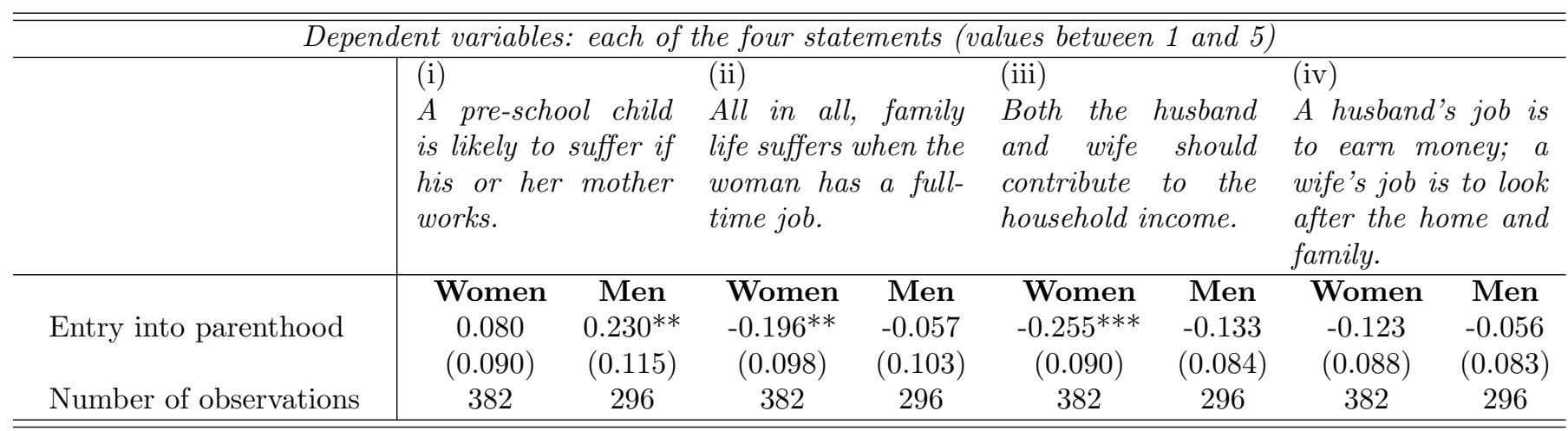

Source: US data set (waves 2 and 4 )

Robust standard errors in parentheses; ${ }^{* *},{ }^{* *}$, and ${ }^{*}$ denote, respectively, the $1 \%, 5 \%$, and $10 \%$ significance level. All the estimations include the same set of controls used in Table 3. 
Table 5: The impact of entry into parenthood on women's and men's gender role attitudes: time since childbirth; fixed effects regressions.

\begin{tabular}{l|cc}
\hline \hline Dependent variable: gender role attitudes (score variable; values between 4 and 20) \\
\hline & Women & Men \\
\hline Entry into parenthood - between 0 and 1 year before & -0.490 & 0.064 \\
& $(0.339)$ & $(0.329)$ \\
Entry into parenthood - between 1 and 2 years before & $-0.498^{*}$ & -0.086 \\
& $(0.279)$ & $(0.344)$ \\
\hline Number of observations & 382 & 296 \\
\hline \hline
\end{tabular}

Source: US data set (waves 2 and 4 )

Robust standard errors in parentheses; ${ }^{* *},{ }^{* *}$, and ${ }^{*}$ denote, respectively, the $1 \%$, $5 \%$, and $10 \%$ significance level. All the estimations include the same set of controls used in Table 3 .

Table 6: The impact of entry into parenthood on women's and men's gender role attitudes: prenatal progressivism and postnatal exposure to imposed traditional arrangements (1); fixed effects regressions.

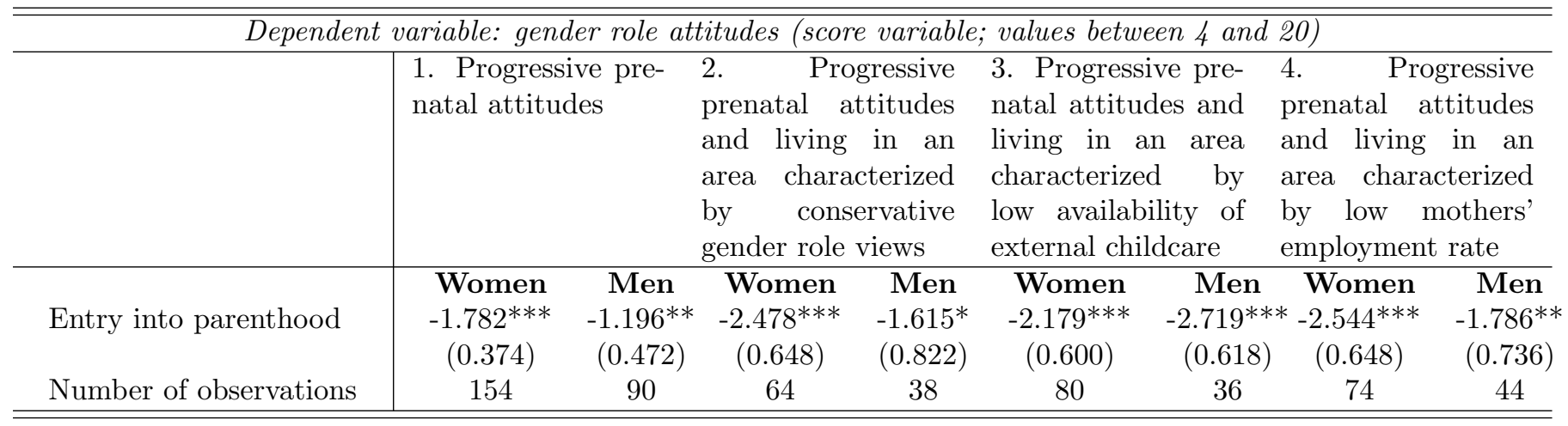

Source: US data set (waves 2 and 4)

Robust standard errors in parentheses; ${ }^{* *},{ }^{* *}$, and ${ }^{*}$ denote, respectively, the $1 \%, 5 \%$, and $10 \%$ significance level. All the estimations include the same set of controls used in Table 3. Attitudes are defined as 'progressive' if the value of the score variable is greater or equal to 16, meaning that the individual agrees or strongly agrees with all the four (recoded) statements. Information on the gender role views, availability of external childcare services, and mothers' employment levels of a particular geographical area is proxied from the complete US data set (wave 1 or wave 2). Local authority districts are the geographical unit of reference. 
Table 7: The impact of entry into parenthood on women's gender role attitudes: prenatal progressivism and postnatal exposure to imposed traditional arrangements (2); fixed effects regressions.

\begin{tabular}{|c|c|c|}
\hline \multicolumn{3}{|c|}{ Dependent variable: gender role attitudes (score variable; values between 4 and 20) } \\
\hline & $\begin{array}{l}\text { 1. Progressive prenatal } \\
\text { attitudes and no use of ex- } \\
\text { ternal childcare }\end{array}$ & $\begin{array}{l}\text { 2. Progressive prenatal } \\
\text { attitudes and transition } \\
\text { into inactivity }\end{array}$ \\
\hline Entry into parenthood & $\begin{array}{l}-1.055^{* * *} \\
(0.378)\end{array}$ & $\begin{array}{l}-1.693^{* * *} \\
(0.383)\end{array}$ \\
\hline No use of external childcare & $\begin{array}{l}-1.786^{* * *} \\
(0.663)\end{array}$ & \\
\hline Transition into inactivity & & $\begin{array}{l}-1.704^{*} \\
(0.907)\end{array}$ \\
\hline Number of observations & 154 & 154 \\
\hline
\end{tabular}

Source: US data set (waves 2 and 4 )

Robust standard errors in parentheses; ***, **, and * denote, respectively, the $1 \%, 5 \%$, and $10 \%$ significance level. All the estimations include the same set of controls used in Table 3 . 


\section{References}

Arcidiacono, P., 2004. Ability Sorting and the Returns to College Major. Journal of Econometrics $121,343-375$.

Baker, M., Gruber, J., Milligan, K., 2008. Universal Child Care, Maternal Labor Supply, and Family Well Being. Journal of Political Economy 116 (4), 709-745.

Baxter, J., Buchler, S., Perales, F., Western, M., 2015. A Life-Changing Event: First Births and Men's and Women's Attitudes to Mothering and Gender Divisions of Labor. Social Forces 93 (3), 989-1014.

Berrington, A., Hu, Y., Smith, P. W. F., Sturgis, P., 2008. A Graphical Chain Model for Reciprocal Relationships between Women's Gender Role Attitudes and Labour Force Participation. Journal of the Royal Statistical Society. Series A (Statistics in Society) 171 (1), 89-108.

Boeckmann, I., Misra, J., Budig, M. J., 2015. Cultural and Institutional Factors Shaping Mothers' Employment and Working Hours in Postindustrial Countries. Social Forces 93 (4), 13011333.

Bolzendahl, C. I., Myers, D. J., 2004. Feminist Attitudes and Support for Gender Equality: Opinion Change in Women and Men, 1974-1998. Social Forces 83 (2), 759-789.

Brandth, B., Kvande, E., 2001. Flexible Work and Flexible Fathers. Work, Employment and Society 15 (2), 251-267.

Brandth, B., Kvande, E., 2002. Reflexive Fathers: Negotiating Parental Leave and Working Life. Gender, Work and Organization 9 (2), 186-203.

Brewster, K. L., Padavic, I., 2000. Change in Gender-Ideology, 1977-1996: The Contributions of Intracohort Change and Population Turnover. Journal of Marriage and Family 62 (2), $477-487$.

Brilli, Y., Del Boca, D., Pronzato, C. D., 2016. Does Child Care Availability Play a Role in Maternal Employment and Children's Development? Evidence from Italy. Review of Economics of the Household 14 (1), 27-51.

Brooks, C., Bolzendahl, C., 2004. The Transformation of US Gender Role Attitudes: Cohort Replacement, Social-Structural Change, and Ideological Learning. Social Science Research 33, 106-133.

Budig, M. J., England, P., 2001. The Wage Penalty for Motherhood. American Sociological Review 66 (2), 204-225. 
Chalabaev, A., Sarrazin, P., Fontayne, P., Boiché, J., Clément-Guillotin, C., 2013. The Influence of Sex Stereotypes and Gender Roles on Participation and Performance in Sport and Exercise: Review and Future Directions. Psychology of Sport and Exercise 14 (2), 136-144.

Ciabattari, T., 2001. Changes in Men's Conservative Gender Ideologies: Cohort and Period Influences. Gender and Society 15 (4), 574-591.

Connelly, R., 1992. The Effect of Child Care Costs on Married Women's Labor Force Participation. The Review of Economics and Statistics 74 (1), 83-90.

Correll, S. J., Benard, S., Paik, I., 2007. Getting a Job: Is There a Motherhood Penalty? American Journal of Sociology 112 (5), 1297-1338.

Corrigall, E. A., Konrad, A. M., 2007. Gender Role Attitudes and Careers: A Longitudinal Study. Sex Roles 56 (11), 847-855.

Cotter, D., Hermsen, J. M., Vanneman, R., 2011. The End of the Gender Revolution? Gender Role Attitudes from 1977 to 2008. American Journal of Sociology 117 (1), 259-289.

Cunningham, M., 2008. Changing Attitudes toward the Male Breadwinner, Female Homemaker Family Model: Influences of Women's Employment and Education over the Lifecourse. Social Forces 87 (1), 299-323.

Cunningham, M., Beutel, A. M., Barber, J. S., Thornton, A., 2005. Reciprocal Relationships between Attitudes about Gender and Social Contexts during Young Adulthood. Social Science Research 34 (4), 862-892.

Cvencek, D., Meltzoff, A. N., Greenwald, A. G., 2011. Math-Gender Stereotypes in Elementary School Children. Child Development 82 (3), 766-779.

Danigelis, N. L., Hardy, M., Cutler, S. J., 2007. Population Aging, Intracohort Aging, and Sociopolitical Attitudes. American Sociological Review 72 (5), 812-830.

Del Boca, D., 2002. The Effect of Child Care and Part Time Opportunities on Participation and Fertility Decisions in Italy. Journal of Population Economics 15 (3), 549-573.

Del Boca, D., Pasqua, S., Pronzato, C., 2009. Motherhood and Market Work Decisions in Institutional Context: a European Perspective. Oxford Economic Papers 61 (suppl. 1), i147i171.

Del Boca, D., Vuri, D., 2007. The Mismatch between Employment and Child Care in Italy: the Impact of Rationing. Journal of Population Economics 20 (4), 805-832. 
Evertsson, M., 2012. The Importance of Work: Changing Work Commitment Following the Transition to Motherhood. Acta Sociologica 56 (2), 139-153.

Ferrer-i Carbonell, A., Frijters, P., 2004. How Important is Methodology for the Estimates of the Determinants of Happiness? The Economic Journal 114 (497), 641-659.

Festinger, L., 1957. A Theory of Cognitive Dissonance. Stanford: Stanford University Press.

Fleming, A. S., Ruble, D., Krieger, H., Wong, P. Y., 1997. Hormonal and Experiential Correlates of Maternal Responsiveness during Pregnancy and the Puerperium in Human Mothers. Hormones and Behavior 31 (2).

Frey, B. S., Stutzer, A., 2000. Happiness, Economy and Institutions. The Economic Journal 110 (466), 918-938.

Frey, B. S., Stutzer, A., 2008. Stress that Doesn't Pay: The Commuting Paradox. The Scandinavian Journal of Economics 110 (2), 339-366.

Gangl, M., Ziefle, A., 2009. Motherhood, Labor Force Behavior, and Womens Careers: An Empirical Assessment of the Wage Penalty for Motherhood in Britain, Germany, and the United States. Demography 46 (2), 341-369.

Gornick, J. C., 2004. Women's Economic Outcomes, Gender Inequality and Public Policy: Findings from the Luxembourg Income Study. Socio-Economic Review 2 (2), 213-238.

Hirsh, B. T., 2005. Why Do Part-Time Workers Earn Less? The Role of Worker and Job Skills. Industrial \& Labor Relations Review 58 (4), 525-551.

Kane, E. W., 1995. Education and Beliefs about Gender Inequality. Social Problems 42 (1), $74-90$.

Lewis, J., 1992. Gender and the Development of Welfare Regimes. Journal of European Social Policy 2 (3), 159-173.

Mandel, H., Semyonov, M., 2005. Family Policies and Gender Gaps. American Sociological Review 70 (6), 949-967.

Manning, A., Petrongolo, B., 2009. The Part-Time Pay Penalty for Women in Britain. The Economic Journal 118 (526), F28-F51.

Moors, G., 2003. Estimating the Reciprocal Effect of Gender Role Attitudes and Family Formation: A Log-Linear Path Model with Latent Variables. European Journal of Population 19 (2), 199-221. 
Pettit, B., Hook, J., 2005. The Structure of Women's Employment in Comparative Perspective. Social Forces 84 (2), 779-801.

Pomerleau, A., Bolduc, D., Malcuit, G., Cossette, L., 1990. Pink or Blue: Environmental Gender Stereotypes in the First two Years of Life. Sex Roles 22 (5), 359-367.

Riedl, M., Geisheckerb, I., 2014. Keep it Simple: Estimation Strategies for Ordered Response Models with Fixed Effects. Journal of Applied Statistics 41 (11), 2358-2374.

Russo, G., Hassink, W., 2008. The Part-Time Wage Gap: A Career Perspective. De Economist $156(2), 145-174$.

Schober, P., Scott, J., 2012. Maternal Employment and Gender Role Attitudes: Dissonance among British Men and Women in the Transition to Parenthood. Work, Employment and Society $26(3), 515-530$.

Sjöberg, O., 2010. Ambivalent Attitudes, Contradictory Institutions: Ambivalence in GenderRole Attitudes in Comparative Perspective. International Journal of Comparative Sociology $51(1-2), 33-57$.

Storey, A. E., Walsh, C. J., Quinton, R. L., Wynne-Edwards, K. E., 2000. Hormonal Correlates of Paternal Responsiveness in New and Expectant Fathers. Evolution and Human Behavior 21 (2), 79-95.

Turner, S. E., Bowen, W. G., 1999. Choice of Major: The Changing (Unchanging) Gender Gap. Industrial \& Labor Relations Review 52 (2), 289-313.

Wozny, C., Schneider, M. R., 2014. A Matter of Degree: the Continuing Training Gap for Women in Europe. Socio-Economic Review 12 (2), 353-379. 
DEPARTMENT OF ECONOMICS AND STATISTICS

UNIVERSITY OF TORINO

Corso Unione Sovietica 218 bis - 10134 Torino (ITALY)

Web page: http://esomas.econ.unito.it/ 